Research Article

\title{
Maternal drinking behavior and Fetal Alcohol Spectrum Disorders in adolescents with criminal behavior in southern Brazil
}

Wakana Momino ${ }^{1,2}$, Têmis Maria Félix ${ }^{2}$, Alberto Mantovani Abeche ${ }^{3}$, Denise Isabel Zandoná ${ }^{2}$, Gabriela Gayer Scheibler ${ }^{2}$, Christina Chambers ${ }^{4}$, Kenneth Lyons Jones ${ }^{4}$, Renato Zamora Flores ${ }^{1}$ and Lavínia Schüler-Faccini ${ }^{1,2}$

${ }^{I}$ Departamento de Genética, Universidade Federal do Rio Grande do Sul, Porto Alegre, RS, Brazil.

${ }^{2}$ Serviço de Genética Médica, Hospital de Clínicas de Porto Alegre, Porto Alegre, RS Brazil.

${ }^{3}$ Departamento de Ginecologia e Obstetrícia, Faculdade de Medicina,

Universidade Federal do Rio Grande do Sul, Porto Alegre, RS, Brazil.

${ }^{4}$ Department of Pediatrics, Division of Dysmorphology and Teratology, University of California, San Diego, USA.

\begin{abstract}
Prenatal alcohol exposure can have serious and permanent adverse effects. The developing brain is the most vulnerable organ to the insults of prenatal alcohol exposure. A behavioral phenotype of prenatal alcohol exposure including conduct disorders is also described. This study on a sample of Brazilian adolescents convicted for criminal behavior aimed to evaluate possible clinical features of Fetal Alcohol Syndrome (FAS). These were compared to a control group of school adolescents, as well as tested for other environmental risk factors for antisocial behavior. A sample of 262 institutionalized male adolescents due to criminal behavior and 154 male students aged between 13 and 21 years comprised the study population. Maternal use of alcohol was admitted by $48.8 \%$ of the mothers of institutionalized adolescents and by $39.9 \%$ of the school students. In this sample of adolescents we could not identify individual cases with a clear diagnosis of FAS, but signs suggestive of FASD were more common in the institutionalized adolescents. Social factors like domestic and family violence were frequent in the risk group, this also being associated to maternal drinking during pregnancy. The inference is that in our sample, criminal behavior is more related to complex interactions between environmental and social issues including prenatal alcohol exposure.
\end{abstract}

Keywords: Prenatal alcohol exposure, fetal alcohol spectrum disorder, criminal behavior, conduct disorder, FAS, FASD.

\section{Introduction}

Prenatal alcohol exposure can have serious and permanent adverse effects on children, whith the most severe outcome being the Fetal Alcohol Syndrome (FAS). It is characterized by a dysmorphic face with short palpebral fissure, smooth philtrum, and thin upper lip, pre- or postnatal growth deficiency, and central nervous system abnormalities. The intensity of these features varies and is manifested in a dose dependent fashion in a way that affected individuals can exhibit all the characteristics or only some of these. Thus, it constitutes a continuum of pattern that has been denoted as Fetal Alcohol Spectrum Disorder (FASD) (Jones et al., 2010).

Send correspondence to Lavínia Schüler-Faccini. Departamento de Genética, Universidade Federal do Rio Grande do Sul, Caixa Postal 15053, 91501-970 Porto Alegre, RS, Brazil. E-mail: lavinia.faccini@ufrgs.br.
Research on alcohol teratogenesis has demonstrated that the developing brain is the organ which is most vulnerable to the effects of prenatal alcohol exposure (Goodlett and Horn, 2001). This teratogen acts in different ways depending on the type of brain cells and developmental stage of the embryo or fetus It can lead to cell death, interfere with cellular functions, hinder the generation of new cells, cause abnormal cell migration and disorganized cell tissue structure, interfere in neurotransmitter production, and cause abnormal formation of neural synapses (Goodlett and Horn, 2001, Guerri et al., 2009). Thus, there is no greatest period of vulnerability and all trimesters during pregnancy appear to be critical for normal brain development (Streissguth et al., 1996).

Although the most common behavioral manifestation of the central nervous system alteration caused by prenatal alcohol exposure is a reduction in intellectual functions, deficits in social behavior are becoming a widespread mark in FASD individuals (Spohr et al, 2007; Kelly et al, 2009). 
Certain studies suggested that these children have behavioral and emotional difficulties that can interfere with their participation in home, school and social environments. Adolescents and adults often exhibit poor socialization and communication skills. The majority displays significant maladaptative behaviors such as impulsivity and inappropriate sexual behavior, and they are less likely to be living independently (Streissguth et al., 1991; Baumbach, 2002; Fast and Conry, 2004; Spohr et al. 2007).

FASDs are frequently associated with impaired behavior, cognitive deficits and secondary disabilities, and more than $90 \%$ of affected individuals show mental health problems, disrupted school experience $(60 \%)$, trouble with the law $(60 \%)$, confinement $(50 \%)$, inappropriate sexual behavior (50\%) and alcohol/drug problems (30\%) (Streissguth et al., 1996). Children prenatally exposed to alcohol present deficits in all domains of adaptative functioning. Their conduct shows a pattern of behavior that is predominately disruptive and overactive-inattentive which can not be explained simply by a lower IQ (Momino et al.,2008; McGee et al., 2009). These problematic behaviors occur in individuals that were prenatally exposed to alcohol, independent of whether they meet the criteria for FAS (Mattson et al., 1998; McGee et al., 2009).

Criminal behavior among adolescents is an important problem in Brazil (Phebo and Moura, 2005). We do not have information about the incidence of FAS/FASD in Brazil, and it is a question whether this condition could be contributing to the adverse conduct seen in our young population. This study aimed to evaluate a sample of institutionalized teenagers regarding maternal use of alcohol during pregnancy and incidence of physical signs of FAS. We also included in our analyses other environmental risk factors that could be related to antisocial behavior.

\section{Subjects and Methods}

The sample consisted of institutionalized males from FASE (Socio-educative Foundation), in Porto Alegre, RS, Brazil, randomly collected during the period of January 2003 to June 2004. FASE is a public institution that holds all teenagers from 12 to 21 years that committed a crime and were condemned. The main crimes committed by institutionalized males were robbery $(50 \%)$, murder $(15 \%)$, theft $(9 \%)$ and robbery followed by death $(7 \%)$; so the only point that distinguishes them from subjects institutionalized in an adult correctional system is age.

The control group consisted of 145 male students attending either elementary or high school levels in three public schools in Porto Alegre, RS, Brazil. For both groups, males between the ages of 13 and 21 years whose parents or guardians agreed to sign the informed consent were selected as eligible for participation. An exclusion criterion was refusal to sign informed consent. Both groups had been classified as middle/low class.
FAS diagnostic signs were defined according the guidelines of the Institute of Medicine (Hoyme et al., 2005), as follows: (i) intrauterine or postnatal growth deficiency with height and/or weight at less than the $10^{\text {th }}$ percentile, (ii) craniofacial dysmorphology including smooth philtrum, thin vermilion, and small palpebral fissures, (iii) central nervous system damage that is either structural or neurological, and (iv) prenatal alcohol exposure, which may be confirmed, unknown, or disconfirmed. For this diagnosis, all study subjects were examined by a physician or a medical student trained in a standard protocol by a dysmorphologist. The physical examination consisted of measuring height, weight, head circumference, palpebral fissure length, inner canthal distance, and philtrum length.

A questionnaire was completed by the mother or by the legal guardian, focusing on alcohol consumption during pregnancy and other maternal characteristics chosen as an indication of the quality of the pregnancy, including pregnancy complications and family history of alcoholism. Due to the long delay since pregnancy, maternal recall of alcohol use was classified as 'none', 'light to moderate', or 'sporadic' meaning less than daily, and 'heavy' meaning daily use of alcohol or binge drinking during pregnancy.

Abortion attempts together with bleeding during pregnancy, delivery problems, and use of medicine were our indicators of pregnancy quality. Familial history included five other variables: mental retardation in the family, physical abuse of the child, positive history of domestic violence, relatives with drinking problems, and positive history of criminality in the family.

Raven's Standard Progressive Matrices, a non-verbal test, was used as the intelligence measurement tool (Raven, 2000).

Descriptive statistics and $\chi^{2}$-test were used to summarize and compare the profile of the studied population. Multiple logistic regression analysis was used to determine if the use of alcohol during pregnancy was associated with covariates. Continuous physical measurements and Ravens cognitive performance scores were compared using oneway ANOVA. Categorical measurements were compared using $\chi^{2}$-tests. Categorization of outcomes by photographic analysis also was by a $\chi^{2}$-test.

The Ethics Committee of Hospital de Clinicas de Porto Alegre approved this project and its informed consent form.

\section{Results}

Maternal characteristics and family history in the group of institutionalized (FASE) adolescents and in the control group are shown in Table 1. Maternal interviews were possible in only $178(68 \%)$ mothers. Prenatal alcohol use was reported by $48.4 \%$ of the mothers of FASE adolescents and by $39.9 \%$ of the mothers of the control group. This difference was not statistically significant. On the 
Table 1 - Pregnancy quality and familial history in adolescents with criminal behavior (FASE) and in the school students (controls).

\begin{tabular}{|c|c|c|c|c|c|}
\hline \multirow[t]{2}{*}{ Variables } & \multicolumn{2}{|c|}{ FASE } & \multicolumn{2}{|c|}{ Controls } & \multirow[t]{2}{*}{$\mathrm{p}^{*}$} \\
\hline & $\mathrm{N}$ & $\%$ & $\mathrm{n}$ & $\%$ & \\
\hline \multicolumn{6}{|l|}{ Drinking habits } \\
\hline None & 92 & 51.6 & 58 & 60.4 & 0.336 \\
\hline Sporadic & 69 & 38.8 & 32 & 33.3 & \\
\hline Frequent & 17 & 9.7 & 6 & 6.3 & \\
\hline \multicolumn{6}{|l|}{ Pregnancy events } \\
\hline Abortion attempt & 17 & 9.7 & 11 & 11.6 & 0.607 \\
\hline Bleeding & 24 & 13.9 & 13 & 13.4 & 0.914 \\
\hline Delivery problem & 23 & 13.2 & 8 & 8.1 & 0.198 \\
\hline Use of medicines & 27 & 20.1 & 19 & 19.6 & 0.915 \\
\hline Breastfeeding & 24 & 13.7 & 8 & 8.1 & 0.171 \\
\hline \multicolumn{6}{|l|}{ Other variables } \\
\hline Domestic violence & 67 & 37.6 & 12 & 12.4 & $<0.001$ \\
\hline Familial criminality & 78 & 43.1 & 19 & 19.6 & $<0.001$ \\
\hline Child abuse & 53 & 29.3 & 4 & 4.2 & $<0.001$ \\
\hline Familial alcoholism & 95 & 65.5 & 65 & 66.3 & 0.896 \\
\hline
\end{tabular}

*Chi-square.

other hand, we could observe a higher frequency of violence indicators among the convicted adolescents' families, such ass domestic violence between the parents, familial criminality, and child abuse.

To verify if the use of maternal alcohol during pregnancy was related to any of the mentioned variables, a multiple logistic regression test was applied. Table 2 shows the
Table 2 - Multiple logistic regression of maternal characteristics and familial history related to alcohol consumption.

\begin{tabular}{lccc}
\hline Variables & Odds ratio & $\begin{array}{c}\text { IC 95\% of the } \\
\text { lowest value }\end{array}$ & $\mathrm{p}$ \\
\hline Bleeding & 0.21 & $0.057-0.741$ & 0.016 \\
Domestic violence & 0.16 & $0.045-0.548$ & 0.004 \\
Familial criminality & 5.31 & $2.135-13.216$ & $<0.001$ \\
Child abuse & 5.86 & $1.538-22.366$ & 0.010 \\
Alcoholism in family & 4.04 & $1.668-9.787$ & 0.002 \\
\hline
\end{tabular}

significant results only of this analysis conducted with the data of 147 families with a positive history of maternal use of alcohol. To minimize bias we used only maternal questionnaires data that contained no missing answers. Bleeding, domestic violence, familial criminality, child abuse, and alcoholism among family members were the five variables found to be associated with maternal alcohol use in this study, with the first two variables having an opposite odds ratio to prenatal alcohol exposition.

Table 3 shows the percentile distribution of physical measurements of the institutionalized males and the control group. For height and head circumference we used percentiles range for comparison. For other measures, means and standard error were used. Considering the hypothesis that FAS signs would be more frequent in convicted adolescents than in those frequenting regular school, we would expect significant differences between both groups. For height, inner canthal distance and intelligence points, the differences were in the expected direction. Head circumference and philtrum length did not differ between groups.

Table 3 - FAS signs in adolescents with criminal behavior (FASE) and in the school students (controls).

\begin{tabular}{|c|c|c|c|c|c|c|}
\hline \multirow[t]{2}{*}{ Variable } & & \multicolumn{2}{|c|}{ FASE } & \multicolumn{2}{|c|}{ Controls } & \multirow[t]{2}{*}{$\mathrm{p}$} \\
\hline & & $\mathrm{n}$ & $\%$ & $\mathrm{n}$ & $\%$ & \\
\hline \multirow[t]{3}{*}{ Height } & Up to $10^{\text {th }}$ percentile & 69 & 37.7 & 16 & 11.2 & $<0.001^{*}$ \\
\hline & $11^{\text {th }}$ to $50^{\text {th }}$ percentile & 130 & 57.8 & 60 & 42.0 & \\
\hline & Above $50^{\text {th }}$ percentile & 26 & 11.5 & 67 & 46.8 & \\
\hline \multirow[t]{4}{*}{ Head circumference } & Up to $10^{\text {th }}$ percentile & 18 & 8.0 & 8 & 5.6 & $0.610^{*}$ \\
\hline & $11^{\text {th }}$ to $50^{\text {th }}$ percentile & 60 & 26.7 & 36 & 25.2 & \\
\hline & Above $50^{\text {th }}$ percentile & 147 & 65.3 & 99 & 69.2 & \\
\hline & & Mean & SE & Mean & SE & \\
\hline Right palpebral fissure length & & 2.86 & 0.017 & 2.73 & 0.021 & $<0.001^{\dagger}$ \\
\hline Left palpebral fissure length & & 2.86 & 0.017 & 2.74 & 0.022 & $<0.001^{\dagger}$ \\
\hline Inner canthal distance & & 3.19 & 0.018 & 3.11 & 0.023 & $0.014^{\dagger}$ \\
\hline Philtrum length & & 1.64 & 0.019 & 1.61 & 0.024 & $0.314^{\dagger}$ \\
\hline Intelligence points & & 32.95 & 0.735 & 38.43 & 0.831 & $<0.001^{\dagger}$ \\
\hline
\end{tabular}

Height and Head circumference are expressed in percentiles; IQ points according to Raven's standard progressive matrices; other measures in $\mathrm{cm}$. *Chi-square.

${ }^{\dagger}$ Analysis of variance SE: standard error. 
More surprisingly however was the fact that palpebral fissure length was significantly smaller in control group.

We also performed a multivariate analysis (ANOVA) comparing physical measures and IQ points between FASE adolescents and school students, considering prenatal exposition to alcohol. This analysis further corroborated the results shown in Table 3.

To better understand this result we separately analyzed anthropometric variables that showed differences taking into account ethnic ancestry in institutionalized and control subjects (Table 4). We observed that mean palpebral fissure length was smaller only in controls classified as of European ancestry. Other measures did not show differences between individuals of different ethnic origins. Mean IQ points, however, were markedly lower only in FASE adolescents of European ancestry.

\section{Discussion}

Our goal was to find out whether there was a prevalence of maternal use of alcohol during pregnancy and incidence of physical signs of FAS in confined young males. In other words we wanted to know how much FAS or fetal alcohol exposure (FAE) may be contributing to juvenile criminal behavior in our society. FAS and FASD are not rare in occidental societies. May et al. (2009) estimated that in the U.S., the prevalence of FAS is in the range of 2-7 per 1000 , and for FASD their estimates were as high as $2-5 \%$ of school children in the US and Western Europe.

FASD is an umbrella term for a wide range of possible consequences of prenatal alcohol exposure. Although the physical expression of this syndrome is not always present, the damage caused in the brain and consequently in behavior is long lasting (Momino et al., 2008). A current discussion in the literature presently is to better characterize the specific behavioral phenotype associated to FASD (Nash et al., 2008; Kodituwakku, 2009), and more specifically criminal behavior. There are few studies in this area, but all of these agree that FAS in the criminal justice system is under diagnosed (Fast et al., 1999; Burd et al., 2004).
Some studies have identified a dose-response effect between prenatal alcohol exposure and behavioral problems taking together both the effects of environmental factors and prenatal alcohol exposure when evaluating the association with behavioral difficulties and psychiatric disorders in affected children (Hill et al., 2000; O'Connor and Paley, 2006; Guerri et al., 2009; Rodriguez et al., 2009). A recent observational cohort study including 592 adolescents observed that those exposed to an average of one or more drinks of alcohol per day in the first trimester of pregnancy were three times more likely to meet criteria for a lifetime diagnosis of conduct disorders than were adolescents whose mothers drank less than that amount or abstained (Larkby et al., 2011). A study performed by Staroselsky et al. (2009) showed that parental psychopathology and prenatal exposure to maternal alcohol can contribute to the child's behavioral phenotype.

We also included in our analyses, the presence of other environmental risk factors that could be related to criminal behavior. Maternal intake of alcohol was admitted by almost $48 \%$ of the mothers of adolescents with criminal behavior. Although this seems high, it was not different from the control group (40\%). Data in the literature denote the use of alcohol in pregnancy from $28 \%$ to $41 \%$ in Brazil (Gama et al., 2004). The 2009 Morbidity and Mortality Weekly Report (MMWR, 2009) showed that in the period from 1991 to 2005, approximately 12\% of pregnant women used alcohol and near $1.9 \%$ engaged in binge drinking or frequent use of alcohol. Ethen et al. (2009) found that nearly one third of women drank alcohol at some time during pregnancy.

Abortion attempts were admitted by almost $10 \%$ of the women. Induced abortion is not legally allowed in Brazil but nonetheless it is quite common practice (Faundes, 2010). Other risk factors present during pregnancy or delivery were concordant with literature data for Brazil (Momino et al., 2003).

The multiple logistic regression test revealed three variables as related to maternal drinking behavior during pregnancy. These were criminality among relatives, being abused

Table 4 - Height, palpebral fissures length and inner canthal distance measures, and cognitive performance in individuals of European and African ancestry.

\begin{tabular}{|c|c|c|c|c|c|c|c|c|c|c|}
\hline \multirow[t]{3}{*}{ Variable } & \multicolumn{5}{|c|}{ European Ancestry } & \multicolumn{5}{|c|}{ African ancestry } \\
\hline & \multicolumn{2}{|c|}{ FASE $(n=118)$} & \multicolumn{3}{|c|}{ Controls $(\mathrm{n}=57)$} & \multicolumn{2}{|c|}{$\operatorname{FASE}(\mathrm{n}=31)$} & \multicolumn{3}{|c|}{ Controls $(n=47)$} \\
\hline & Mean & SE & Mean & SE & $\mathrm{p}$ & Mean & SE & Mean & SE & $\mathrm{p}$ \\
\hline Right palpebral fissure & 168.49 & 0.653 & 170.08 & 0.912 & $0.156^{\dagger}$ & 168.98 & 1.424 & 169.91 & 1.137 & $0.610^{\dagger}$ \\
\hline Left palpebral fissure & 2.75 & 0.019 & 2.67 & 0.026 & $0.014^{\dagger}$ & 2.82 & 4.026 & 2.79 & 3.162 & $0.616^{\dagger}$ \\
\hline Inner canthal distance & 2.76 & 0.019 & 2.68 & 0.026 & $0.025^{\dagger}$ & 2.82 & 4.004 & 2.79 & 3.145 & $0.529^{\dagger}$ \\
\hline Philtrum length & 3.16 & 0.026 & 3.10 & 0.036 & $0.192^{\dagger}$ & 3.26 & 4.789 & 3.20 & 0.038 & $0.332^{\dagger}$ \\
\hline Intelligence points & 33.73 & 0.942 & 39.03 & 1.321 & $0.001^{\dagger}$ & 31.96 & 1.939 & 34.45 & 1.539 & $0.317^{\dagger}$ \\
\hline
\end{tabular}

Height is expressed in cm; IQ points according to Raven's standard progressive matrices.

${ }^{\dagger}$ Analysis of variance SE: standard error. 
during infancy, and a positive history of alcoholism in another member of the family. Domestic violence against the woman was inversely correlated to drinking behavior. Our hypothesis is that domestic violence means that the woman was beaten by her husband mostly when he was drunk, thus generating in the woman avoidance to the use of alcohol.

To obtain an accurate maternal history of alcohol consumption is not always easy or possible. In this sense we tried to detect individuals with FASD regardless of maternal information by using physical sings and neurobehavioral data only. To do so we compared the measurements of the physical examination and the intelligence points of the institutionalized males with those of the public schools students. We opted here to use the percentile for height and head circumference.

Most of the physical measurements showed a significant difference between those two groups regardless of the maternal use of alcohol. Height and philtrum length were affected as expected by a stronger exposure to alcohol among the institutionalized adolescents. Even though the achievement on Raven Progressive Matrices was not different between probands and controls, the very poor results presented by the institutionalized boys are worthy of note, with 35 points being considered the low end of the normal intelligence curve. The low height and low intelligence scores are very heterogeneous in their etiology and therefore with low specificity for prenatal alcohol exposure.

Palpebral fissures, however, were significantly smaller in the control group, which was in the direction opposite from the expected. The fact that the difference was observed only in individuals of European ancestry could be contributing to this result, but we cannot yet explain why.

In conclusion, we could not identify in this sample of adolescents, individual cases with a clear diagnosis of FAS, but signs suggestive of FASD were more common in institutionalized adolescents. The high maternal history for drinking in both groups is also noteworthy. Furthermore, social factors like domestic and familial violence, which are frequent in this group, are also predictors of maternal drinking during pregnancy. From the herein compiled information the inference is that in Brazil criminal behavior is more related to complex interactions among environmental and social issues, these including prenatal alcohol exposure.

\section{Acknowledgments}

This study was supported by $\mathrm{CNPq}$ (Brazilian National Institute of Research). W M received a PhD scholarship from CAPES.

\section{References}

Baumbach J (2002) Some implications of prenatal alcohol exposure for the treatment of adolescents with sexual offending behaviors. Sex Abuse 14:313-327.
Burd L, Selfridge R, Klug M and Bakko S (2004) Fetal alcohol syndrome in the United States corrections system. Addict Biol 9:169-176.

Ethen M, Ramadhani T, Scheuerle A, Canfield MA, Wyszynski DF, Druschel CM, Romitti PA and National Birth Defects Prevention Study (2009) Alcohol consumption by women before and during pregnancy. Matern Child Health J 13:274-285.

Fast DK and Conry J (2004) The challenge of fetal alcohol syndrome in the criminal legal system. Addict Biol 9:161-166.

Fast DK, Conry J and Loock CA (1999) Identifying fetal alcohol syndrome among youth in the criminal justice system. J Dev Behav Pediatr 20:370-372.

Faundes A (2010) Unsafe abortion - The current global scenario. Best Pract Res Clin Obstet Gynaecol 24:467-77.

Gama SGN, Szwarcwald CL, Sabroza AR, Branco VC and Leal MC (2004) Factors associated with precarious prenatal care in a sample of post-partum adolescent mothers in maternity hospitals in Rio de Janeiro, Brazil, 1999-2000. Cad Saúde Pública 20(suppl. 1):101-111.

Goodlett CR and Horn KH (2001) Mechanisms of alcoholinduced damage to the developing nervous system. Alcohol Res Health 25:175-184.

Guerri C, Bazinet A and Riley EP (2009) Foetal Alcohol Spectrum Disorders and alterations in brain and behaviour. Alcohol Alcohol 44:108-114.

Hill SY, Lowers L, Locke-Wellman J and Shen S (2000) Maternal smoking and drinking during pregnancy and the risk for child and adolescent psychiatric disorders. J Stud Alcohol 61:661-668.

Hoyme HE, May PA, Kalberg WO, Kodituwakku P, Gossage JP, Trujillo PM, Buckley DG, Miller JH, Aragon AS, Khaole N, et al. (2005) A practical clinical approach todiagnosis of fetal alcohol spectrum disorders: Clarification of the 1996 iIstitute of Medicine criteria. Pediatrics 115:39-47.

Jones KL, Hoyme HE, Robinson LK, Del Campo M, Manning MA, Prewitt LM and Chambers CD (2010) Fetal alcohol spectrum disorders: Extending the range of structural defects. Am J Med Genet A 152A:2731-2735.

Kelly SJ, Goodlett CR and Hannigan JH (2009) Animal models of fetal alcohol spectrum disorders: Impact of the social environment. Dev Disabil Res Rev 15:200-208.

Kodituwakku PW (2009) Neurocognitive profile in children with fetal alcohol spectrum disorders. Dev Disabil Res Rev 15:218-224.

Larkby CA, Goldschmidt L, Hanusa BH and Day NL (2011) Prenatal alcohol exposure is associated with conduct disorder in adolescence: Findings from a birth cohort. J Am Acad Child Adolesc Psychiatry 50:262-71.

McGee CL, Bjorkquist OA, Price JM, Mattson SN and Riley EP (2009) Social information processing skills in children with histories of heavy prenatal alcohol exposure. J Abnorm Child Psychol 37:817-30.

Mattson SN, Riley EP, Gramling LJ, Delis DC and Jones KL (1998) Neuropsychological comparison of alcohol-exposed children with or without physical features of fetal alcohol syndrome. Neuropsychology 12:146-153.

Mattson SN, Crocker N and Nguyen TT (2011) Fetal alcohol spectrum disorders: Neuropsychological and behavioral features. Neuropsychol Rev 21:81-101. 
May PA, Gossage JP, Kalberg WO, Robinson LK, Buckley D, Manning M and Hoyme HE (2009) Prevalence and epidemiologic characteristics of FASD from various research methods with an emphasis on recent in-school studies. Dev Disabil Res Rev 15:176-192.

MMWR (2009) Alcohol use among pregnant and nonpregnant women of childbearing age - United States, 1991-2005. Morb Mortal Wkly Rep 58:529-532.

Momino W, Minussi L, Woffchuck D, Palmero EI, Sanseverino MT, Guimarães-Fachel JM and Schuler-Faccini L (2003) Reproductive risk factors related to socioeconomic status in pregnant women in southern Brazil. Community Genet 6:77-83.

Momino W, Sanseverino MTV and Schüler-Faccini L (2008) Prenatal alcohol exposure as a risk factor for dysfunctional behaviors: The role of the pediatrician. J Pediatr (Rio de Janeiro) 84:S76-S79.

Nash K, Sheard E, Rovet J and Koren G (2008) Understanding fetal alcohol spectrum disorders (FASDs): Toward identification of a behavioral phenotype. SciWorld J 8:873-882.

O'Connor MJ and Paley B (2006) The relationship of prenatal alcohol exposure and the postnatal environment to child depressive symptoms. J Ped Psychol 31:50-64.

Phebo L and Moura AT (2005) Urban violence: A challenge for pediatricians. J Pediatr (Rio de Janeiro) 81:S189-S96.

Raven J (2000) The Raven's Progressive Matrices: Change and stability over culture and time. Cogn Psychol 41:1-48.

Riley EP, Infante MA and Warren KR (2011) Fetal alcohol spectrum disorders: An overview. Neuropsychol Rev 21:73-80.
Rodriguez A, Olsen J, Kotimaa AJ, Kaakinen M, Moilanen I, Henriksen TB, Linnet KM, Miettunen J, Obel C, Taanila A, et al. (2009) Is prenatal alcohol exposure related to inattention and hyperactivity symptoms in children? Disentangling the effects of social adversity. J Child Psychol Psychiatry 50:1073-1083.

Sood B, Delaney-Black V, Covington C, Nordstrom-Klee B, Ager J, Templin T, Janisse J, Martier S and Sokol RJ (2001) Prenatal alcohol exposure and childhood behavior at age 6 to 7 years: I. Dose-response effect. Pediatrics 108:e34.

Spohr HL, Willms J and Steinhausen HC (2007) Fetal alcohol spectrum disorders in young adulthood. J Pediatr 150:175179.

Staroselsky A, Fantus E, Sussman R, Sandor P, Koren G and Nulman I (2009) Both parental psychopathology and prenatal maternal alcohol dependency can predict the behavioral phenotype in children. Pediatr Drugs 11:22-25.

Streissguth AP, Aase JM, Clarren SK, Randels SP, Ladue RA and Smith DF (1991) Fetal alcohol syndrome in adolescents and adults. JAMA 265:1961-1967.

Streissguth AP, Barr HN, Kogan J and Bookstein FL (1996) Final Report to the $\mathrm{CDC}$ on Understanding the Occurrence of Secundary Disabilities in Fetal Alcohol Syndrome and Fetal Alcohol Effects. University of Washington Press, Seattle, $71 \mathrm{pp}$.

License information: This is an open-access article distributed under the terms of the Creative Commons Attribution License, which permits unrestricted use, distribution, and reproduction in any medium, provided the original work is properly cited. 